\title{
OPTIMIZATION FOR STIFFENERS OF RECTANGULAR SURFACE CONDENSER OPERATING UNDER DIFFERENTIAL EXTERNAL PRESSURE
}

\author{
Yogesh S. Bhore ${ }^{1}$, Dattatray N. Jadhav², Parag D. Mahajan ${ }^{3}$, Sagar S. Mali ${ }^{4}$ \\ ${ }^{1,2}$ Mechanical Engineering Department, Sardar Patel College of Engineering, Mumbai-400058, India \\ ${ }^{3,4}$ Larsen \& Toubro Limited, Heavy Engineering, Powai Works, Mumbai-400072, India
}

\begin{abstract}
Surface condenser operates under differential external pressure during its service life which causes deformation of equipment. Stiffening arrangements are provided in condenser to restrict deformation of equipment within allowable limit. Condenser is the equipment having lot of internals like heater tube, protruded nozzles, baffles, inside piping etc. So, it is essential to optimize location and size of stiffeners.

In the present study sub-assembly of rectangular surface condenser is analysed for optimization of stiffener size. Response surface optimization along with design of experiment methodology is used for stiffener optimization. Design of experiment is carried out with the help of central composite design method. Optimization of stiffener size and location of the stiffener helps to reduce obstruction to steam flow in condenser.
\end{abstract}

Key Words: Response surface optimization, Design of experiment, Central Composite design, Screening optimization, Finite Element Method.

\section{INTRODUCTION}

Surface condenser is the primary equipment of power plant industry. It contains different sub-assemblies like Condenser upper exhaust neck (UEN), Condenser lower exhaust neck (LEN), main condenser etc. as shown in Fig. 1. Steam from turbine piping enters in condenser UEN and gets condensed in main condenser. In the present study condenser UEN is analysed. Condenser UEN is rectangular in cross section and it is bounded by different plates $[1,2]$. Surface condenser is the heat exchanger which operates under vacuum condition. Due to this, equipment is subjected to differential external pressure. This causes deformation of equipment wall plate. Stiffening arrangement like stiffener plate is required for condenser wall strengthening purpose. Guidelines for stiffening arrangement are developed by Heat Exchanger Institute (HEI) standard [3]. As per Indian Standard (IS), allowable limit of deformation for condenser UEN model is $3 \mathrm{~mm}$ [4]. To analyse this case, parametric model is necessary. Stiffener dimensions can be changed easily with the help of parametric model. In present study finite element method is used for analysis purpose of condenser UEN deformation.

Optimization of stiffening arrangement is carried out to restrict the deformation within allowable limit and to reduce the equipment weight. Response surface optimization method (RSM) along with design of experiments (DOE) tool of ANSYS workbench is used. DOE is performed with the help of central composite design (CCD) method.

\section{METHODOLOGIES}

\subsection{Fea Model}

Shell model of condenser UEN along with stiffener plates is shown in Fig. 2. Major dimensions of rectangular condenser UEN section are given in Table 1 .

Table -1: Condenser UEN dimensions

\begin{tabular}{|c|c|c|c|}
\hline Length (mm) & Width (mm) & Height (mm) & $\begin{array}{c}\text { Thickness } \\
(\mathbf{m m})\end{array}$ \\
\hline 7530 & 7126 & 1000 & 16 \\
\hline
\end{tabular}

Element used for meshing of condenser UEN model is shell 181. Material properties [4] for condenser UEN and stiffener plates are tabulated in Table 2.

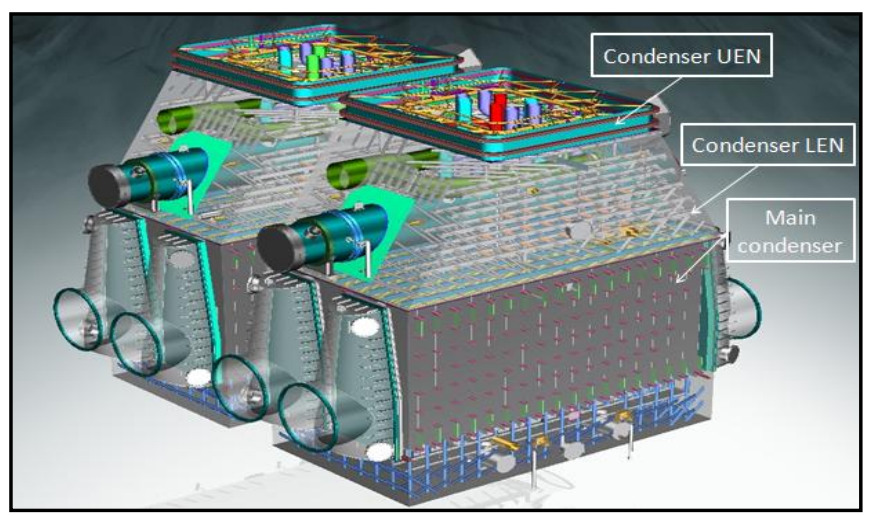

Fig -1: Rectangular surface condenser 
Table -2: Material Properties

\begin{tabular}{|c|c|c|}
\hline Material No. & $\begin{array}{c}\text { Modulus of } \\
\text { Elasticity }\end{array}$ & $\begin{array}{c}\text { Poisson's } \\
\text { ratio }\end{array}$ \\
\hline $\begin{array}{c}\text { IS-2062-Grade B } \\
\text { (Carbon steel) }\end{array}$ & $200 \mathrm{Mpa}$ & 0.3 \\
\hline
\end{tabular}

Boundary conditions applied on model are shown in Fig. 2 where A indicates upper and lower edges are fixed and B indicates differential external pressure $(0.1013 \mathrm{MPa})$ acting normal to condenser UEN.

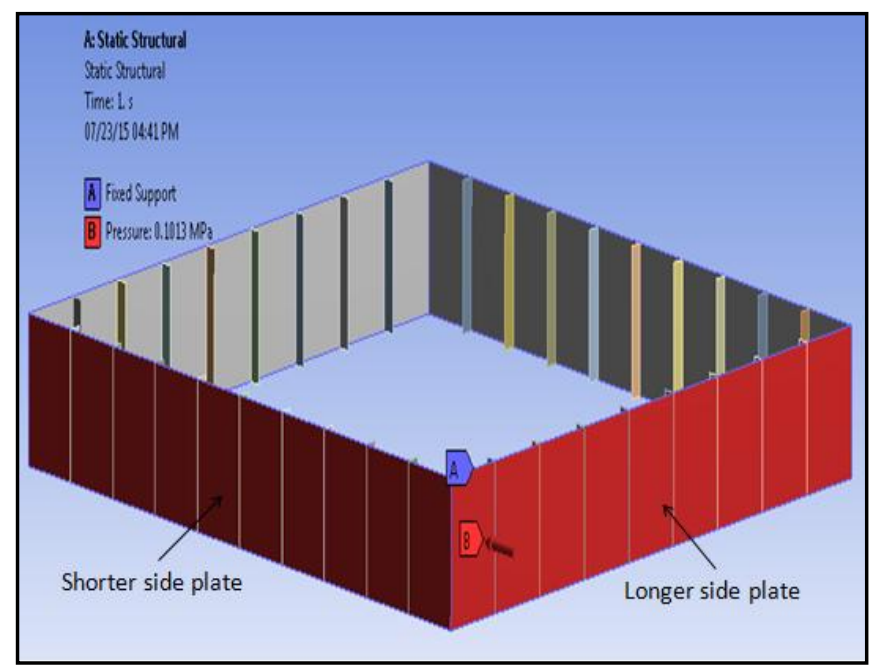

Fig -2: Condenser UEN model with boundary condition

FEA solution shows that deformation of condenser UEN model is $2.26 \mathrm{~mm}$ (see Fig. 3). Stiffener dimensions can be optimized by allowing the deformation to $3 \mathrm{~mm}$ as specified in IS.

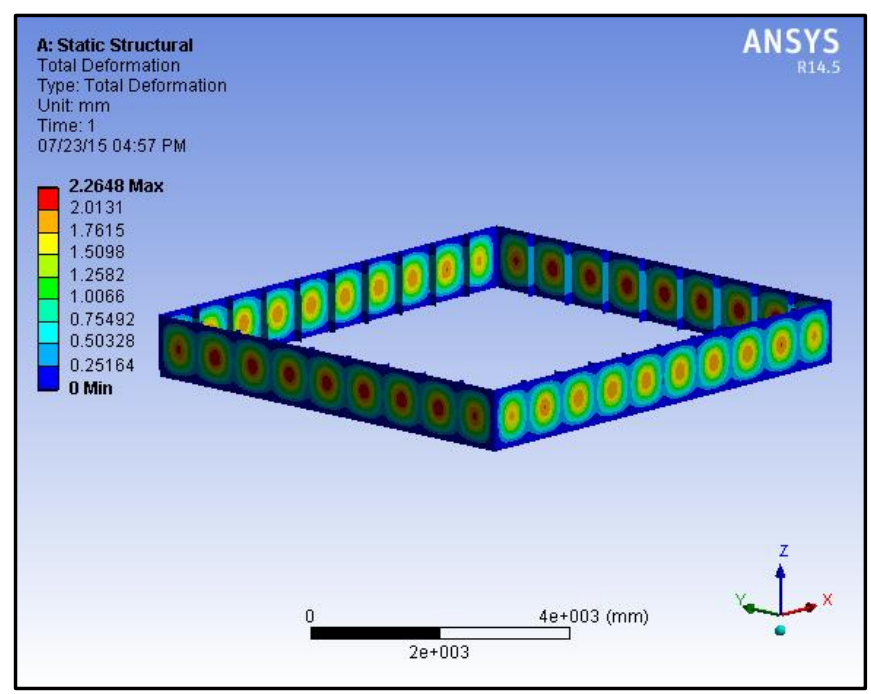

Fig -3: Total deformation of Condenser UEN model

Four input parameters that are selected for optimization of condenser UEN are shown in Fig. 4. Description of these input parameters is given in Table 3. Other input parameters such as stiffener spacing and stiffener plate thickness are optimized according to HEI standard.

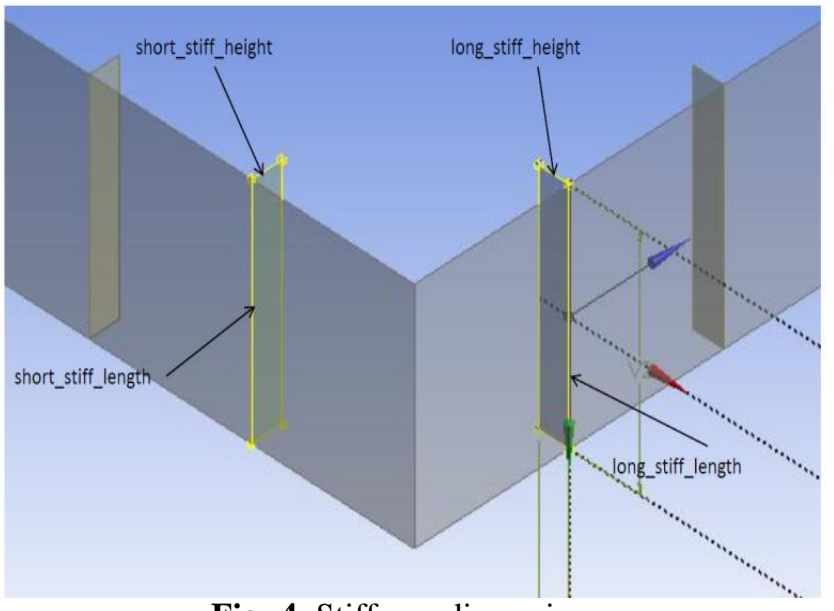

Fig -4: Stiffener dimensions

Table -3: Input parameter description

\begin{tabular}{|l|l|}
\hline $\begin{array}{c}\text { Input } \\
\text { parameter }\end{array}$ & \multicolumn{1}{c|}{ Parameter description } \\
\hline short_stiff_height & $\begin{array}{l}\text { Height of the stiffener present over } \\
\text { shorter side plate of UEN model }\end{array}$ \\
\hline short_stiff_length & $\begin{array}{l}\text { Length of the stiffener present over } \\
\text { shorter side plate of UEN model }\end{array}$ \\
\hline long_stiff_height & $\begin{array}{l}\text { Height of the stiffener present over } \\
\text { longer side plate of UEN model }\end{array}$ \\
\hline long_stiff_length & $\begin{array}{l}\text { Length of the stiffener present over } \\
\text { longer side plate of UEN model }\end{array}$ \\
\hline
\end{tabular}

\subsection{Response surface optimization}

In this optimization, system draws information from its own response surface component, and so is dependent on the quality of the response surface.

RSM is efficient goal driven optimization method as it gives accurate enough results with less computation time compared to other optimization techniques [5].

Response surface optimization has following steps,

- Design of Experiments

- Generating a response surface

- Response Surface Optimization

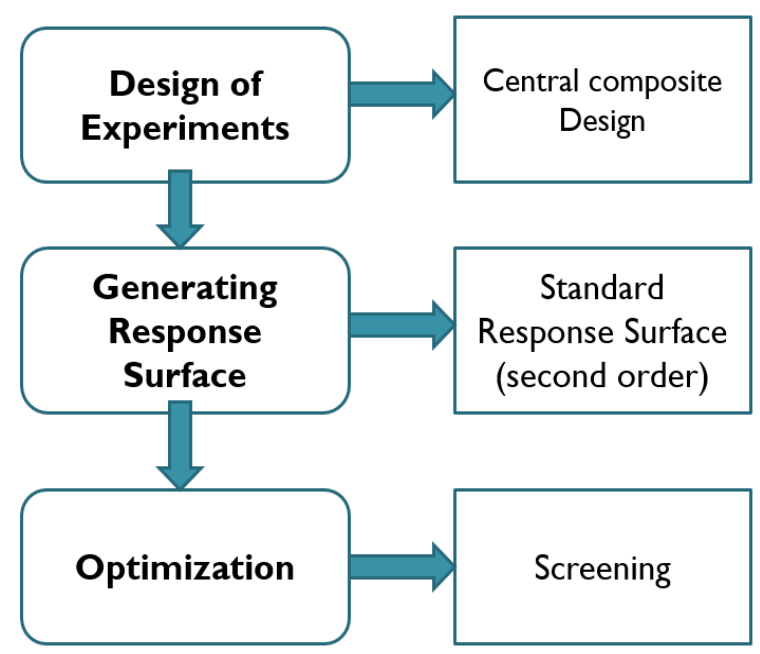

Fig -5: Steps in Response surface optimization 


\section{DESIGN OF EXPERIMENTS}

DOE [5] is a technique used to scientifically determine the location of sampling points. DOE technique has characteristic of locating the sampling points such that the space of random input parameters is explored in the most efficient way.

\subsection{Central Composite Design}

CCD [5], also known as Box-Wilson Design, is factorial design that is suitable for calibrating the quadratic response model.

For present study Inscribed CCD is used as it evenly distributes sampling points around the center point. For condenser UEN optimization, CCD consists of following sampling points:

- Center point $=1$

- $2 * \mathrm{~N}$ axis points $=8$

- $2^{(\mathrm{N}-\mathrm{f})}$ diagonal points $=16$

Here, $\quad \mathrm{N}=$ Number of random input variables $=4$ $\mathrm{f}=0$ (Full-factorial design)

Upper and lower limit for input parameters along with its initial value is tabulated in Table 4 .

Table -4: Lower and upper bound limit for input parameters

\begin{tabular}{|c|c|c|c|}
\hline Parameter name & Value & $\begin{array}{c}\text { Lower } \\
\text { Bound }\end{array}$ & $\begin{array}{c}\text { Upper } \\
\text { Bound }\end{array}$ \\
\hline short_stiff_height $(\mathbf{m m})$ & 150 & 100 & 150 \\
\hline short_stiff_length $(\mathbf{m m})$ & 1000 & 700 & 1000 \\
\hline long_stiff_height $(\mathbf{m m})$ & 150 & 100 & 150 \\
\hline long_stiff_length $(\mathbf{m m})$ & 1000 & 700 & 1000 \\
\hline
\end{tabular}

Total 25 sampling points generated in DOE are tabulated in Table 5. Distribution of 25 sampling points is shown with 25 different colour lines (see Fig. 6) e.g. Total deformation and geometry mass for $25^{\text {th }}$ sample (Black line) along with its input parameter is indicated in Fig. 6.

\section{3 responses Surface}

Response surfaces are the functions of different nature where the output parameters are described in terms of the input parameters. Response surface is generated with the help of non-linear regression analysis.

For generating response surface, standard response surface (second order polynomial) is preferred along with CCD as it gives good quality response surface compared with all other methods [6]. Response surfaces for four input parameters are shown in Fig. 7 to Fig. 10.

\section{3 screening Optimization}

The Screening optimization method [7] is used for optimization purpose as it uses a simple approach based on sampling and sorting. It supports multiple objectives and constraints for all types of input parameters.

Configuration for given problem is 50 samples and 1 optimized candidate point.

Objectives and Constraints are,
[1]. Maximize Total Deformation; Total Deformation $<=3$ $\mathrm{mm}$ (As initial total deformation is low, Objective function is maximize)

[2]. Minimize Geometry Mass

Table -5: Sampling points generated in DOE of condenser UEN

\begin{tabular}{|c|c|c|c|c|}
\hline $\begin{array}{l}\text { Sr. } \\
\text { No }\end{array}$ & $\begin{array}{l}\text { short_stiff } \\
\text { height } \\
(\mathrm{mm})\end{array}$ & $\begin{array}{l}\text { short_stiff } \\
\text { length } \\
(\mathrm{mm})\end{array}$ & $\begin{array}{l}\text { long_stiff__ } \\
\text { height } \\
(\mathrm{mm})\end{array}$ & $\begin{array}{l}\text { long_stiff__ } \\
\text { length } \\
(\mathrm{mm})\end{array}$ \\
\hline 1 & 125 & 850 & 125 & 850 \\
\hline 2 & 100 & 850 & 125 & 850 \\
\hline 3 & 150 & 850 & 125 & 850 \\
\hline 4 & 125 & 700 & 125 & 850 \\
\hline 5 & 125 & 1000 & 125 & 850 \\
\hline 6 & 125 & 850 & 100 & 850 \\
\hline 7 & 125 & 850 & 150 & 850 \\
\hline 8 & 125 & 850 & 125 & 700 \\
\hline 9 & 125 & 850 & 125 & 1000 \\
\hline 10 & 107 & 744 & 107 & 744 \\
\hline 11 & 143 & 744 & 107 & 744 \\
\hline 12 & 107 & 956 & 107 & 744 \\
\hline 13 & 143 & 956 & 107 & 744 \\
\hline 14 & 107 & 744 & 143 & 744 \\
\hline 15 & 143 & 744 & 143 & 744 \\
\hline 16 & 107 & 956 & 143 & 744 \\
\hline 17 & 143 & 956 & 143 & 744 \\
\hline 18 & 107 & 744 & 107 & 956 \\
\hline 19 & 143 & 744 & 107 & 956 \\
\hline 20 & 107 & 956 & 107 & 956 \\
\hline 21 & 143 & 956 & 107 & 956 \\
\hline 22 & 107 & 744 & 143 & 956 \\
\hline 23 & 143 & 744 & 143 & 956 \\
\hline 24 & 107 & 956 & 143 & 956 \\
\hline 25 & 143 & 956 & 143 & 956 \\
\hline
\end{tabular}

\section{RESULTS AND DISCUSSION}

Total deformation and geometry mass distribution for 25 sampling points is shown in Fig. 6. Fig. 7 and Fig. 8 indicates that total deformation decreases as stiffener dimension increases while Fig. 9 and Fig. 10 indicates that geometry mass increases as stiffener dimension increases.

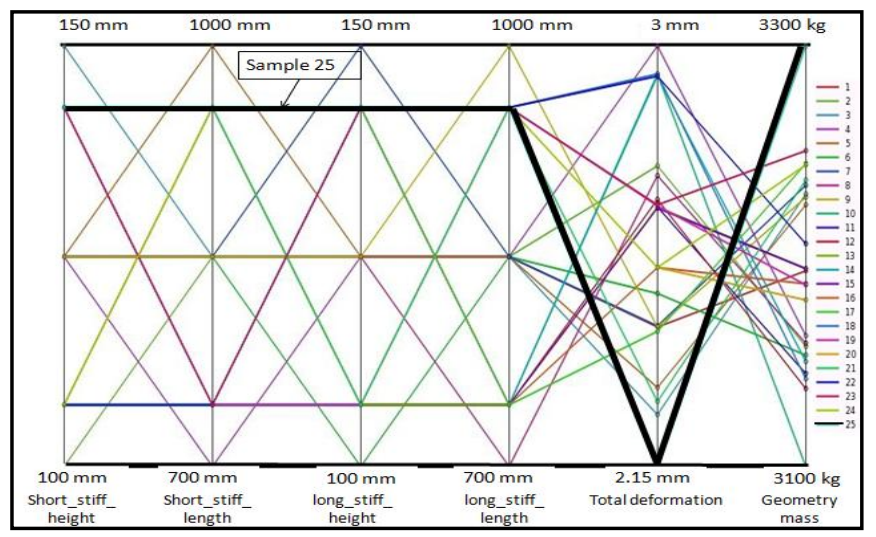

Fig -6: Sample distribution in DOE 


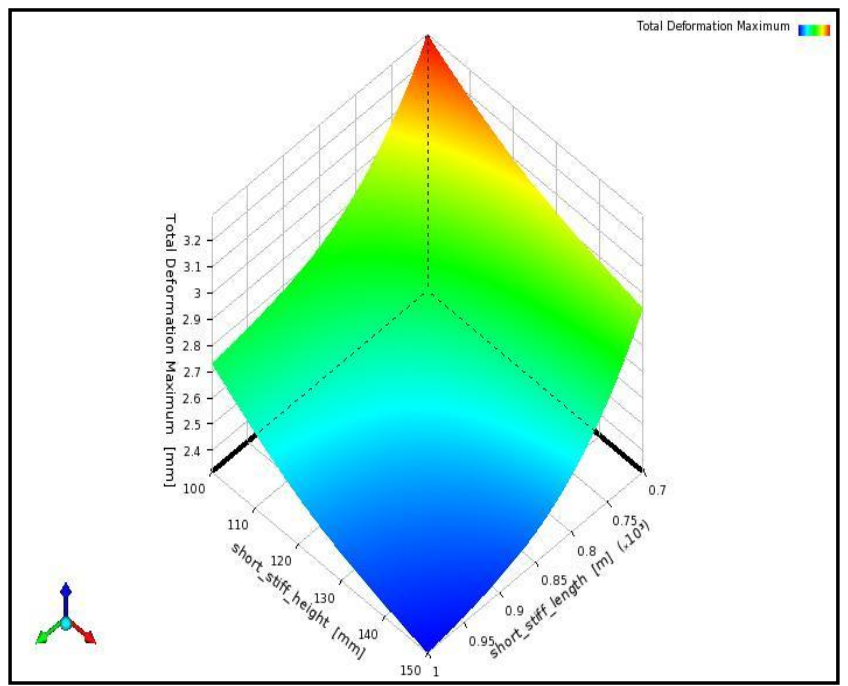

Fig -7: Effect of short_stiff_height and short_stiff_length on Total Deformation

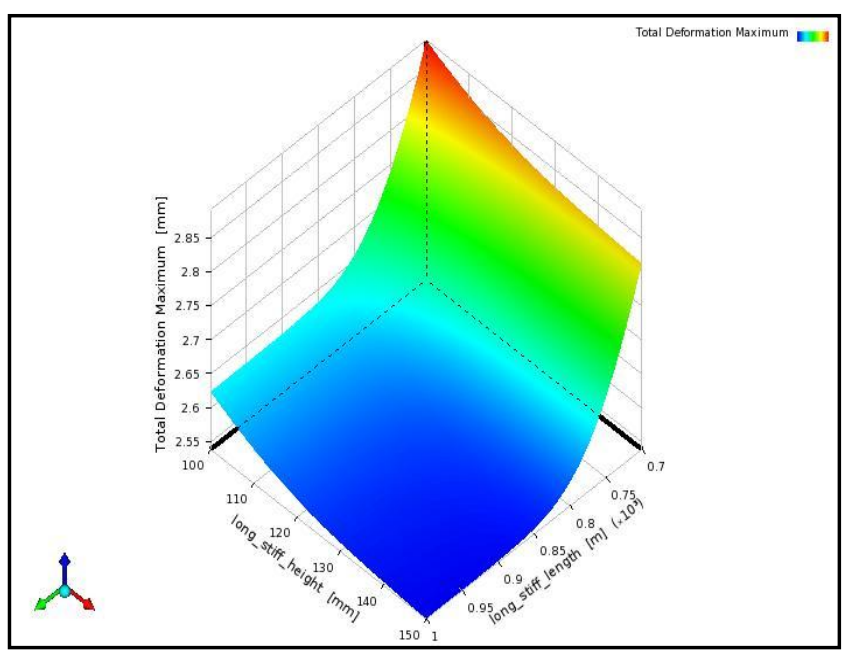

Fig -8: Effect of long_stiff_height and long_stiff_length on Total Deformation

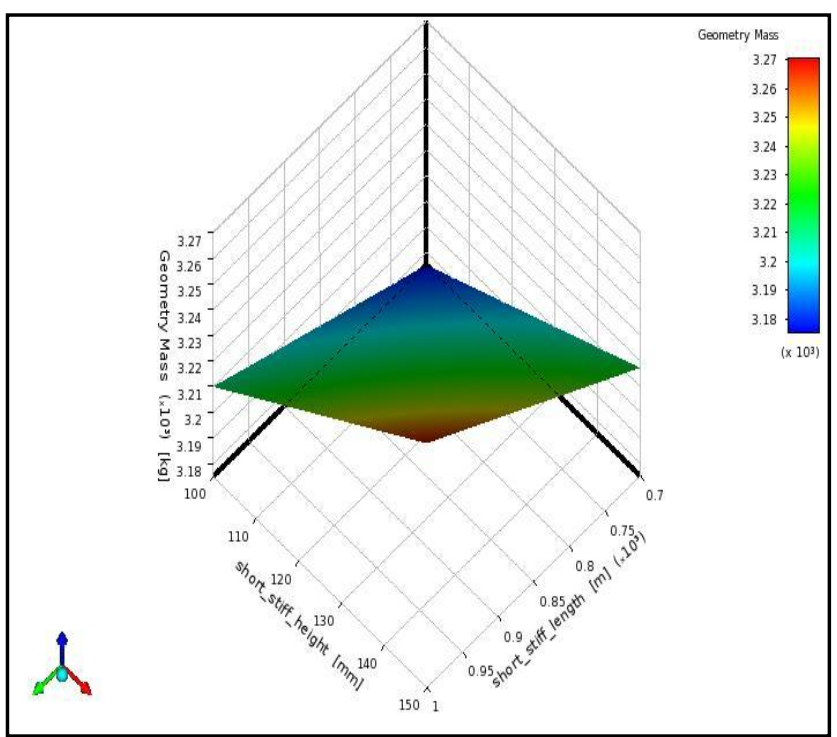

Fig -9: Effect of short_stiff_height and short_stiff_length on Geometry mass

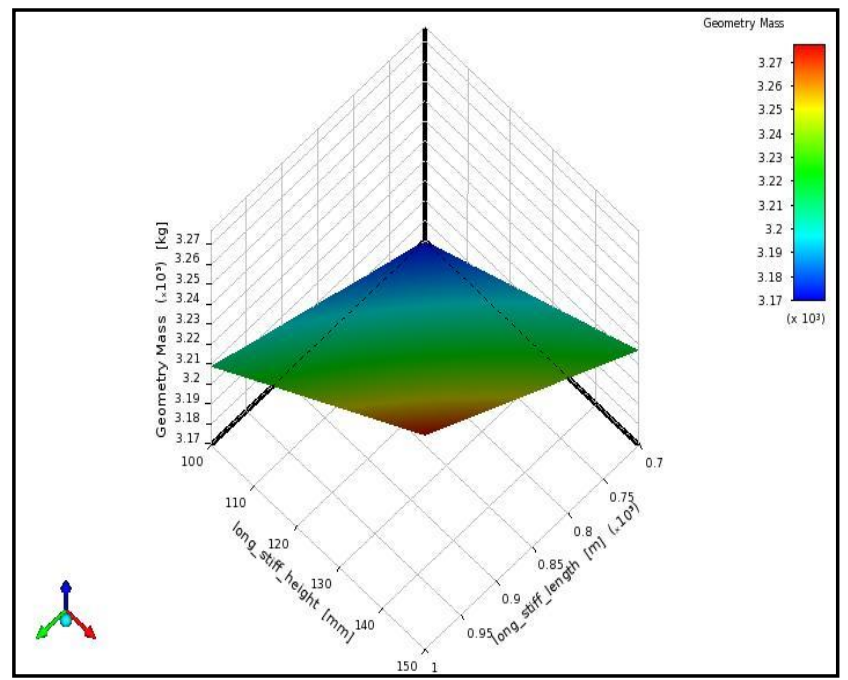

Fig -10: Effect of long_stiff_height and long_stiff_length on Geometry mass

Optimized candidate point with reduced stiffener dimensions is shown in Table 6.

Table -6: Optimized point with FEA verification

\begin{tabular}{|c|c|c|}
\hline Input parameter & $\begin{array}{c}\text { Optimized } \\
\text { Point } \\
\text { (Screening } \\
\text { method) }\end{array}$ & $\begin{array}{c}\text { Optimized } \\
\text { Point } \\
\text { (Verified by } \\
\text { FEA) }\end{array}$ \\
\hline short_stiff_height(mm) & \multicolumn{2}{|c|}{109} \\
\hline short_stiff_length(mm) & \multicolumn{2}{|c|}{750} \\
\hline long_stiff_height (mm) & \multicolumn{2}{|c|}{750} \\
\hline long_stiff_length (mm) & & \\
\hline Maximum Total & 2.9606 & \\
Deformation (mm) & & \\
\hline Geometry Mass (kg) & 3157 & \\
\hline
\end{tabular}

Decrease in stiffener dimension causes considerable reduction in stiffener plate weight as well as steam flow obstruction area. (See Table 7)

Table -7: Weight and obstruction area reduction in stiffener plates of condenser UEN

\begin{tabular}{|c|c|c|c|}
\hline $\begin{array}{c}\text { UEN } \\
\text { part }\end{array}$ & $\begin{array}{c}\text { Percentage } \\
\text { weight reduction }\end{array}$ & $\begin{array}{c}\text { Percentage reduction } \\
\text { in obstruction area }\end{array}$ & \\
\hline Stiffeners & 45.33 & 27.33 & \\
\hline
\end{tabular}




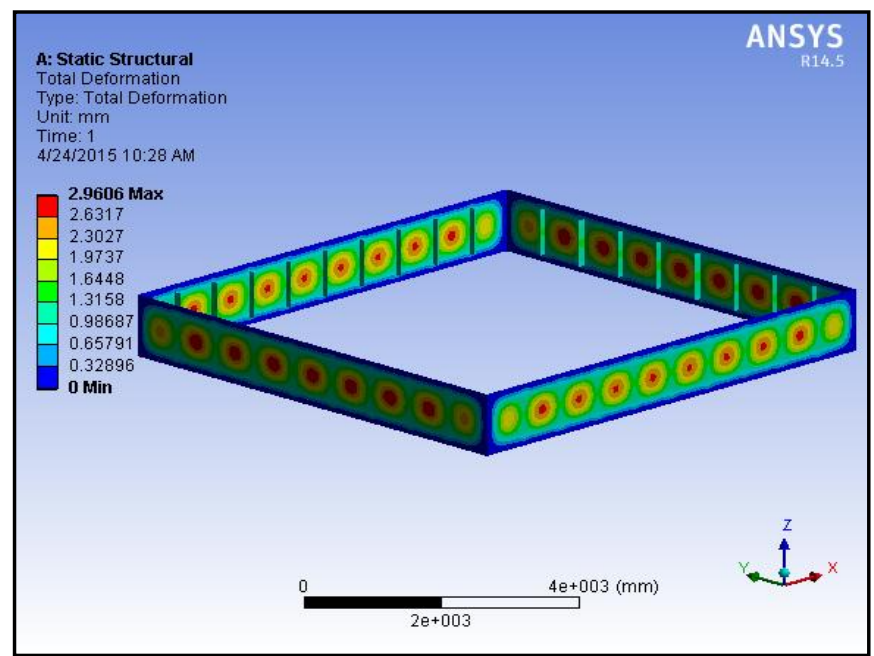

Fig -11: Total Deformation of optimized plate stiffened condenser UEN

\section{CONCLUSION}

The conclusion derived from above study can be summarized as follows:

[1]. Parametric FEA model provides better flexibility in terms of design changes.

[2]. Significant increase in total deformation occurs when stiffener length (for both longer and shorter side of UEN) decreases from $850 \mathrm{~mm}$ to $700 \mathrm{~mm}$.

[3]. Significant increase in total deformation occurs when stiffener height (for both longer and shorter side of UEN) decreases from $125 \mathrm{~mm}$ to $100 \mathrm{~mm}$.

[4]. Geometry mass increases linearly as stiffener dimension increases.

[5]. Optimized point determined by screening method is verified by performing FEA (within $1 \%$ error).

[6]. Optimization of stiffening arrangement reduces the stiffener plate weight by $45 \%$.

[7]. Optimization also helps to reduce the obstruction to steam flow (27.33\% reduction in obstruction area).

\section{REFERENCES}

S. Timoshenko and S. Woinowsky Krieger. Theory of plates and shells. 1989

[1]. Warren c. Young, Richard g. Budynas. Roark's Formulas for Stress and Strain. 2003.

[2]. Heat Exchanger Institute. Standards for steam surface condenser. 2006.

[3]. Indian Standard-2062. 2007.

[4]. Lennart Eriksson. Design of Experiments: Principles and Applications. 2008.

[5]. S.N. Deming, S.L. Morgan. Experimental Design: A Chemometric Approach. 1993.

[6]. ANSYS 14.5 Manual-2014. 